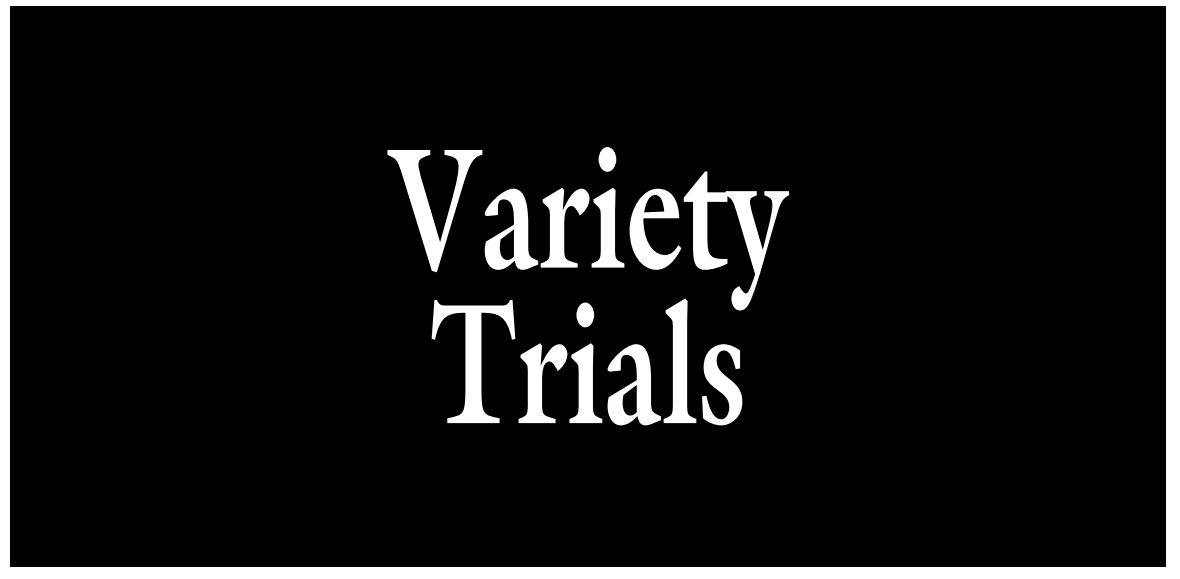

\section{Evaluation of Flower, Fruit, and Juice Characteristics of a Multinational Collection of Cider Apple Cultivars Grown in the U.S. Pacific Northwest}

\author{
Carol A. Miles ${ }^{1}$, Jacqueline King, Travis Robert Alexander, and \\ Edward Scheenstra
}

ADDITIONAL INDEX WORDs. biennial bearing, bloom density, juice quality, Malus $\times$ domestica, alcohol by volume

SUMMARY. Little information exists on the bloom and fruit characteristics of cider apple (Malus $\times$ domestica) cultivars grown in the United States for the juice and alcoholic beverage markets. In this study, a total of 17 cider apple cultivars, including 4 American, 9 English, and 4 French, plus 1 Danish standard dessert apple cultivar (Red Gravenstein, Worthen strain) commonly used for cider, all grown in northwest Washington, were evaluated from 2000 to 2015 for commercially relevant traits. Trees were rated each year and the cultivars were categorized accordingly by relative bloom time, bloom habit, and productivity. The mean full bloom (FB) date of the 18 apple cultivars evaluated ranged from 25 Apr. to 25 May, with 6 cultivars categorized as early season bloomers, 9 as midseason, and 3 as late season. The mean bloom density (BD) rating (measured on a scale of 1-5) for all cultivars was (mean $\pm \mathrm{SD}$ ) $3.8 \pm 0.6$ (moderate bloom), with the bloom habit of 1 cultivar categorized as biennial, 11 as consistent, and 6 as strongly consistent. The mean productivity rating (measured on a scale of 1-5) for all cultivars was $2.9 \pm 0.6$ (light fruiting), with the productivity of 4 cultivars categorized as biennial, 10 as consistent, and 4 as strongly consistent. The mean fruit diameter of the 18 apple cultivars was $2.7 \pm 0.4$ inches (medium sized), with the fruit size of 2 cultivars categorized as small-fruited, 15 as medium-fruited, and 1 as large-fruited. For the 18 cultivars, the mean tannin and titratable acidity (TA) were $0.20 \% \pm 0.14 \%$ and $0.54 \% \pm 0.28 \%$, respectively, and using the English cider apple classification system of juice type, 4 of the cultivars were classified as bittersweet, 1 as bittersharp, 3 as sweet, and 10 as sharp. Three of the cultivars had tannin content lower than what was historically recorded at the Long Ashton Research Station (LARS) in Bristol, England, for those same cultivars. The mean specific gravity (SG) of the 18 cultivars was $1.052 \pm 0.007$, the average predicted alcohol by volume $(\mathrm{ABV})$ was $6.9 \% \pm 0.9 \%$, and the mean $\mathrm{pH}$ was $3.68 \pm 0.39$. Classification of three cultivars in northwest Washington, based on juice characteristics, differed from their historical classification in England, likely because of differences in climate and management. Only cultivars Golden Russet (sharp), Grimes Golden (sharp), and Yarlington Mill (sweet, but borderline bittersweet) were strongly consistent in productivity, but none produced high levels of tannin, whereas only cultivars Bramtot (bittersweet), Chisel Jersey (bittersweet), and Breakwell Seedling (bittersharp) were consistent in productivity and produced high levels of tannin.

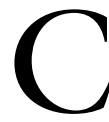
ider is fermented apple juice with up to $8.5 \% \mathrm{ABV}$ [Alcohol and Tobacco Tax and Trade
Bureau (TTB), 2015] and is sometimes referred to as "hard cider" in the United States. Cider has a long history in the United States, but there is little information regarding the productivity and quality of cider apples grown in this country. Such data are available in countries such as England, France, and Sweden (Beech and Carr, 1977; Heikefelt, 2011; Power, n.d.; Williams, 1987), and compared in publications such as Alwood (1903) which specifically concluded that cider apple data can vary greatly "in the different countries and in different parts of the same country." Nine years after first landing in America at Plymouth in 1620, European colonists planted apple trees in Massachusetts Bay, New England (Orton, 1995). By the 1670s, orchards in New England were producing up to 500 barrels or a little more than 32,000 gal (at 64 gal per barrel) of cider annually in some communities (Bender, 2009). In 1721, several villages in New England reported cider production of more than $192,000 \mathrm{gal}$ a year per village (Williams, 1990). Most homesteads had an apple orchard, apples were pressed for juice, and fermentation was the easiest way to preserve the beverage beyond the harvest season (Orton, 1995). Until the late 1800s, cider was the most popular alcoholic beverage made and consumed in the United States; however, by the early 1900s, cider had essentially disappeared from U.S. markets (Proulx and Nichols, 1997). At that time, the Industrial Revolution brought people from the farm to the city, and orchards were gradually abandoned resulting in reduced production. At the same time, the arrival of beer-drinking immigrants from Germany and Ireland and the concurrent availability of inexpensive grain from the midwestern United States resulted in a rapid increase in beer production in urbanizing areas. Further, unfiltered and unpasteurized cider did not store or travel well from farms to the new urban centers. Finally, farmers in sympathy with the Temperance movement cut down their cider orchards, whereas others started pasteurizing their pressed juice and marketing it as nonalcoholic apple juice (Watson, 1999; Williams, 1990). By the time Prohibition was enacted in 1919, the production of cider in the United States had fallen to 13 million gallons, down from 55 million gallons in 1899 (Watson, 1999). Over the next several decades, the American 
tradition of cider making was kept alive only by a few local farmers and enthusiasts (Orton, 1995).

Cider is currently experiencing a revival in the United States, and although it accounts for only $1 \%$ of the alcoholic beverage market, it is the fastest growing alcohol market segment, with an average of $56 \%$ increase in production each year from 2007 to 2015 (Morton, 2013; TTB, 2016). In 2007, 775,031 gal of cider were produced in the United States; this increased 22 -fold to $17,101,697$ gal in 2015. The volume of cider produced in Washington State grew by more than 25 -fold between 2007 and 2015 , from 44,387 gal to $1,099,823$ gal, a $29 \%$ average increase each year, and accounted for $5.7 \%$ of the total U.S. cider production in 2007 and $6.4 \%$ in 2015 (TTB, 2016). The number of cideries in Washington increased 19-fold in this time period, from three cideries in 2007 to 56 in 2015, whereas nationally in 2015 there were 541 cideries in 44 states, with only New York state (65 cideries) having more cideries than Washington (Northwest Cider Association, 2016; The Cyder Market, 2015).

Apple cultivars are categorized for cider making based on their tannin and acid contents, with bittersharp and bittersweet categories of the English system (Table 1) considered the most desirable for producing highquality, full-bodied ciders (Alwood, 1903; Barker, 1903, 1911; Barker and Burroughs, 1953; Bore and Fleckinger, 1997; Buell, 1869; Trowbridge, 1917; Williams, 1975). In the French classification system, which is the second-most commonly used categorization system for cider, aigre amère (acid and bitter) is equivalent to bittersharp, amère (bitter) is equivalent to full

Department of Horticulture, Washington State University, 16650 State Route 536, Mount Vernon, WA 98273

Technical support for this project was provided by Jonathan Roozen, Andrew Zimmerman, Kyle Craig, and Karen Hasenoerhl. Funding support for this project is gratefully acknowledged from the Washington State Department of Agriculture, the Washington State University Center for Sustaining Agriculture and Natural Resources, the Northwest Agricultural Research Foundation, the Northwest Cider Association, and State project WN00427-Acc. No.1000194. Recognition is also given to Gary Moulton who established the initial orchard trial in 1994 and directed its further expansion and initial data collection.

${ }^{1}$ Corresponding author. E-mail: milesc@wsu.edu. doi: 10.21273/HORTTECH03659-17

Table 1. Cider apple classification systems developed in England at the Long Ashton Research Station in Bristol (Barker, 1903; Barker and Burroughs, 1953) and in France (Bore and Fleckinger, 1997; Jolicoeur, 2013).

\begin{tabular}{lcc}
\hline Classification system & Tannin $(\%)^{\mathbf{z}}$ & Acid $(\%)^{\mathbf{y}}$ \\
\hline English & & \\
Bittersweet & $>0.20$ & $<0.45$ \\
Bittersharp & $>0.20$ & $>0.45$ \\
Sharp & $<0.20$ & $>0.45$ \\
Sweet & $<0.20$ & $<0.45$ \\
French & & \\
Douce (sweet) & $<0.20$ & $<0.40$ \\
Douce amère (sweet and bitter) & $0.20-0.30$ & $<0.40$ \\
Amère (bitter) & $>0.30$ & $<0.40$ \\
Acidulée (mildly acid) & $<0.20$ & $0.40-0.60$ \\
Aigre (acid) & $<0.20$ & $>0.60$ \\
Aigre amère (acid and bitter) & $>0.30$ & $>0.60$ \\
\hline
\end{tabular}

${ }^{\mathrm{z}}$ Tannin expressed as tannic acid equivalents.

${ }^{\text {y } T i t r a t a b l e ~ a c i d i t y ~ e x p r e s s e d ~ a s ~ m a l i c ~ a c i d ~ e q u i v a l e n t s . ~}$

bittersweet, aigre (acid) is equivalent to sharp, and douce amere (sweet and bitter) is equivalent to mild bittersweet in the English classification system (Jolicoeur, 2013). Most dessert apples fall into the sweet or sharp categories, without bitterness; these apple types tend to be accessible in every region and so cider makers will often blend these with fruit of less available bittersharp and bittersweet cultivars (Merwin et al., 2008; Moulton et al., 2010). Although most cider apple cultivars used today originated in Europe, by the mid-1800s farmers in the United States had selected American heirloom cultivars such as Harrison, Granniwinkle, Campfield, and Hewes' Virginia Crab for their superior cider qualities (Morgan and Richards, 1993; Orton, 1995). In addition, older dessert apple cultivars like Northern Spy, Baldwin, Golden Russet, and Roxbury Russet were used for cider making (Merwin et al., 2008).

U.S. cultivars were not included in the English orchard where cider apples were assayed for cider making, and so there is limited information regarding how they would be classified. The objective of this study was to evaluate 17 cider apple cultivars and one reference standard dessert apple cultivar of European and U.S. heritage, all grown in northwest Washington and observed for 5 to 14 years, for bloom characteristics, productivity, and juice quality characteristics. This information provides the most comprehensive descriptive data of numerous cider apples grown in the United States. Although this information may be of most value to growers and cider makers in western Washington, growers and cider experts throughout the United States will benefit as this new information contributes to a better understanding of how each cultivar responds to soil and climate conditions in a different region.

\section{Materials and methods}

OrChard establishment. A 0.5 -acre cider apple orchard was established from 1994 to 2008 at Washington State University Mount Vernon Northwest Washington Research and Extension Center (WSU Mount Vernon NWREC) in Mount

\begin{tabular}{llll}
\hline $\begin{array}{l}\text { Units } \\
\begin{array}{l}\text { To convert U.S. to SI, } \\
\text { multiply by }\end{array}\end{array}$ & U.S. unit & SI unit & $\begin{array}{l}\text { To convert SI to U.S., } \\
\text { multiply by }\end{array}$ \\
\hline 0.4047 & acre(s) & $\mathrm{ha}$ & 2.4711 \\
29.5735 & $\mathrm{fl} \mathrm{oz}$ & $\mathrm{mL}$ & 0.0338 \\
0.3048 & $\mathrm{ft}$ & $\mathrm{m}$ & 3.2808 \\
3.7854 & gal & $\mathrm{L}$ & 0.2642 \\
0.7457 & horsepower & $\mathrm{kJ} \cdot \mathrm{s}^{-1}$ & 1.3410 \\
2.54 & inch $(\mathrm{es})$ & $\mathrm{cm}$ & 0.3937 \\
1.6093 & mile $(\mathrm{s})$ & $\mathrm{km}$ & 0.6214 \\
28.3495 & $\mathrm{oz}$ & $\mathrm{g}$ & 0.0353 \\
6.8948 & $\mathrm{psi}$ & $\mathrm{kPa}$ & 0.1450 \\
$\left({ }^{\circ} \mathrm{F}-32\right) \div 1.8$ & ${ }^{\circ} \mathrm{F}$ & ${ }^{\circ} \mathrm{C}$ & $\left({ }^{\circ} \mathrm{C} \times 1.8\right)+32$ \\
& & &
\end{tabular}


Table 2. Apple cultivars planted in a nonreplicated research orchard (3-5 subsamples) at Washington State University Mount Vernon Northwest Washington Research and Extension Center (Mount Vernon, WA) including country of origin, rootstock, and date of establishment.

\begin{tabular}{lllc}
\hline Cultivar & \multicolumn{1}{c}{ Origin } & Rootstock $^{\mathbf{z}}$ & Plant date \\
\hline Bramley's Seedling & England & M.26 & 2002 \\
Bramtot & England & M.9 & 2006 \\
Breakwell Seedling & England & M.26 & 2002 \\
Bulmer's Norman & France (En) & M.M.106 & 2002 \\
Campfield & United States & M.M.106 & 2005 \\
Chisel Jersey & England & M.M.106 & 2008 \\
Golden Russet & United States & M.26 & 2002 \\
Gravenstein, Red (Worthen) & Denmark & M.9 & 2008 \\
Grimes Golden & United States & M.9 & 2006 \\
Harrison & United States & M.M.106 & 2005 \\
Kermerrien & France & M.M.106 & 2005 \\
Kingston Black & England & M.M.106 & 2002 \\
Maude & England & M.9 & 2006 \\
Redstreak, Hereford & England & M.M.106 & 2002 \\
Ross Nonpareil & France (Ir) & M.9 & 2006 \\
Tramlett's, Geneva & England & M.M.106 & 2005 \\
Vilberie & France & M.M.106 & 1994 \\
Yarlington Mill & England & M.M.106 & 1994 \\
\hline
\end{tabular}

${ }^{\mathrm{z}}$ M.9 = Malling 9, M.26 = Malling 26, MM.106 = Malling-Merton 106.

${ }^{y}$ Cultivar originated in France, renamed in England (En) or Ireland (Ir).

'Geneva Tramlett's' is a tentative designation; uncertainty exists whether what was received from USDA Geneva, NY was the true 'Tramlett's Bitter'.

Vernon, WA. The orchard site has soil type Skagit silt loam, classified as a fine-silty, mixed, nonacid, mesic Typic Fluvaquent recently formed of alluvium and volcanic ash (USDA, 2013). Cultivars in this study include 17 specialty cider apple cultivars from England (9), France (4), and the United States (4), plus 1 standard dessert apple cultivar commonly used for cider from Denmark (Red Gravenstein, Worthen strain) (Table 2). Rootstocks (Malling series) have been shown to vary in their influence on the bloom time, $\mathrm{BD}$, and productivity of scions (Webster, 1995), and so to avoid generalizations, the specific rootstock ['Malling 9' (M.9), 'Malling 26' (M.26), or 'Malling-Merton 106' (MM.106)] on which each scion was observed is specified in Table 2. Cultivars were randomly planted in the research orchard, with three to five trees per cultivar planted next to each other; trees were planted at a spacing of $12 \mathrm{ft}$ in the row and $16 \mathrm{ft}$ between rows. All trees were maintained on a central leader system with tree canopy depth of 4 to $8 \mathrm{ft}$, and received the same fertilizer, irrigation, pesticide, and fruit thinning applications each year following recommended commercial practices for the region (Moulton and King, 2003; Stebbins, 1992). The standard dessert apple cultivar Red Gravenstein was included in the study to provide a comparison with a well-known cultivar, and was grown in an adjacent orchard block for the entire study period. Data were collected each year from 2000 to 2015 , starting for each cultivar when it was well established in the orchard.

ENVIRONMENTAL MEASUREMENTS. WSU Mount Vernon NWREC is located at lat. $48^{\circ} 26^{\prime} 21^{\prime} \mathrm{N}$, long. $122^{\circ} 23^{\prime} 15^{\prime} \mathrm{W}$, elevation $23 \mathrm{ft}$ above mean sea level, and 5 miles from the Salish Sea. In general, the climate year round is cool maritime, with an average air temperature of $58{ }^{\circ} \mathrm{F}, 77 \%$ relative humidity, and 13.9 inches of precipitation during the growing season (March to September), and an average air temperature of $44{ }^{\circ} \mathrm{F}, 86 \%$ relative humidity, and 18.4 inches of precipitation during the dormant season [October to February (Washington State University, 2015)]. During this study, temperature was recorded every $5 \mathrm{~s}$ and summarized every $15 \mathrm{~min}$ by a WSU AgWeatherNet station located 0.4 miles from the orchard.

Bцоом. Beginning in mid-April, trees were observed once per week until FB (when first petals of the king bloom began to drop) was reached and recorded; data were collected a minimum of 6 years, and an average of 9 years were recorded for the 18 cultivars. Based on the average FB date, the relative bloom time of each cultivar was categorized as early, mid, or late. $\mathrm{BD}$ was subjectively rated on a scale of 1 to 5 , where $1=$ sparse to no bloom, unproductive; $2=$ light bloom; $3=$ moderate bloom; $4=$ abundant bloom; and $5=$ snowball bloom, requiring thinning to avoid possible biennial bearing habit (adapted from Micke et al., 1991). Based on an index of BD (BDI), the bloom habit of each cultivar was categorized as: strongly biennial $(0.90 \leq \mathrm{BDI} \leq$ $1.00)$; biennial $(0.50 \leq \mathrm{BDI}<0.90)$; consistent $(0.10<\mathrm{BDI}<0.50)$; or strongly consistent $(0.00 \leq \mathrm{BDI} \leq$ $0.10)$. BDI was calculated as the absolute difference in BD between two consecutive years divided by their sum, and index values were averaged over the period of evaluation (adapted from Hoblyn et al., 1936).

Preharvest Fruit LOAD. In Sept. 2011-14, the productivity of each cultivar was rated by visual estimation on a scale of 1 to 5 , where: $1=$ sparse to no fruit; $2=$ light fruiting; $3=$ moderate fruiting; $4=$ abundant fruiting; and 5 = overloaded fruiting, multiple fruit per spur with loaded branches bending to the ground. Based on an index of biennial bearing (BBI), the productivity of each cultivar was categorized as: strongly biennial $(0.90 \leq \mathrm{BBI} \leq 1.00)$; biennial $(0.50 \leq \mathrm{BBI}<0.90) ;$ consistent $(0.10<\mathrm{BBI}<0.50)$; or strongly consistent $(0.00 \leq \mathrm{BBI} \leq 0.10)$. BBI was calculated as the absolute difference in productivity rating between two consecutive years divided by their sum, and index values were averaged over the period of evaluation (adapted from Wilcox, 1944).

Fruit size. From Sept. to Oct. 2000-15, three fruit of each cultivar were sampled once per week to monitor maturity using the starch iodine test (Blanpied and Silsby, 1992). Fruit were harvested from a tree when an average starch index value of 8.5 was reached on the nine-point BC/Ontario scale (Chu and Wilson, 2000; Lau, 1988). Two cider cultivars, Chisel Jersey and Kingston Black, did not give consistent readings in starch tests, and in such cases, soluble solids concentration, skin and seed color, and ease of release of stems from spurs were used as harvest metrics. In 2013-15, fruit diameter (inches) was measured for 25 fruit selected randomly for each cultivar. Based on the average 
diameter, the relative size class of each cultivar's fruit was categorized as: small (1.6-2.3 inches), medium (2.4-3.1 inches), or large (3.2-3.9 inches).

JUICE QUALITY CHARACTERISTICS. At harvest, 15 to 25 representative ripe fruit were collected for each cultivar (fruit were collected from each of four quadrats per tree) and stored up to 1 week in cold storage at $37^{\circ} \mathrm{F}$; data were collected a minimum of 5 years, and an average of 7 years for the 18 cultivars were recorded. Fruit samples in 2002-12 were shredded and pressed with a Correll Cider Press (Standard Large with 5-gal capacity and 0.3-horsepower shredder; Cider Press, Veneta, OR), and in 2013-15 were shredded with a fruit mill (MuliMax 30 with a 2.8-horsepower shredder; Zambelli Enotech, Camisano Vicentino, Italy) and pressed with a bladder press (Carezza with 10.5-gal capacity, Enotechnica Pillan, Camisano Vicentino, Italy). After processing each sample, the equipment was cleaned with a water hose with a highpressure attachment (line pressure 42 psi). Each year, juice samples were collected in $250-\mathrm{mL}$ plastic bottles and frozen $\left(-15^{\circ} \mathrm{C}\right)$ until harvest of all cultivars was completed.

Juice samples were thawed to room temperature $\left(23^{\circ} \mathrm{C}\right)$, handshaken for homogenization, and then measured for tannin, TA, SG, and $\mathrm{pH}$. Tannin was measured using the Lowenthal permanganate titration method
(Burroughs and Whiting, 1960; Lea, 2008; Lowenthal, 1877). For each juice sample, $1 \mathrm{~mL}$ juice was added to $150 \mathrm{~mL}$ distilled water, and then $5 \mathrm{~mL}$ indigo carmine solution $[1 \mathrm{~g}$ indigo carmine, $\mathrm{l} \mathrm{L}$ distilled water, and $50 \mathrm{~mL}$ concentrated sulfuric acid $\left.\left(\mathrm{H}_{2} \mathrm{SO}_{4}\right)\right]$ was added. The mixture was titrated with a solution of $0.005 \mathrm{M}$ potassium permanganate $\left(\mathrm{KMnO}_{4}\right)$ until yellow color was observed and was comparable in color to the indicator blank. The indicator blank consisted of $5 \mathrm{~mL}$ indigo carmine solution mixed with $150 \mathrm{~mL}$ distilled water and titrated with potassium permanganate until yellow color was observed. The proportion of tannin for each sample was calculated using the equation: Tannin [expressed as tannic acid equivalents (percent)] = $(X-\Upsilon) / 10$, where $X$ is the amount of potassium permanganate added to the sample, and $\Upsilon$ is the amount of potassium permanganate added to the indicator blank. TA was measured for each sample by combining $25 \mathrm{~mL}$ juice and $100 \mathrm{~mL}$ distilled water in a $250-\mathrm{mL}$ beaker, stirring with a magnetic stir bar, and titrating with $0.2 \mathrm{~N}$ sodium hydroxide $(\mathrm{NaOH})$ to a $\mathrm{pH}$ reading of 8.1 (Gallander et al., 1991). The volume (milliliters) of sodium hydroxide added was recorded and TA [expressed as malic acid equivalents (percent)] was calculated using the equation: $\mathrm{TA}=$ $(\mathrm{mL} 0.2 \mathrm{~N} \mathrm{NaOH} \times 0.536) / 10$. Based on the tannin and TA results, cultivars were classified according to the English cider classification system established at the LARS [Bristol, England (Barker, 1903)] (Table 1). SG was measured with a hydrometer [SG range 1.000-1.070, temperature calibration $60{ }^{\circ} \mathrm{F}$ (VeeGee Scientific, Kirkland, WA)]; readings were corrected for temperature differential when applicable. The predicted ABV for each cultivar was calculated using the equation: $\mathrm{ABV}=[(\mathrm{SG}-1.0) \times$ 1000] / 7.5. Juice $\mathrm{pH}$ was measured for each sample using a digital $\mathrm{pH}$ meter (Orion 3 Star; Thermo Scientific, Pittsburg, PA).

Statistical analysis. Basic summary statistics and regression analysis were performed using JMP software (version 12.0.0 for Windows; SAS Institute, Cary, NC).

\section{Results and Discussion}

Temperature. The 15-year monthly average air temperature range at WSU Mount Vernon NWREC was 53 to $58{ }^{\circ} \mathrm{F}$ during the growing season, and 40 to $46^{\circ} \mathrm{F}$ during the dormant season (Fig. 1). The 15-year monthly minimum temperature range was 45 to $49{ }^{\circ} \mathrm{F}$ during the growing season and 35 to $40{ }^{\circ} \mathrm{F}$ during the dormant season. The 15-year monthly maximum temperature range was 62 to $68{ }^{\circ} \mathrm{F}$ during the growing season and 47 to $53{ }^{\circ} \mathrm{F}$ during the dormant season. In general, temperatures did

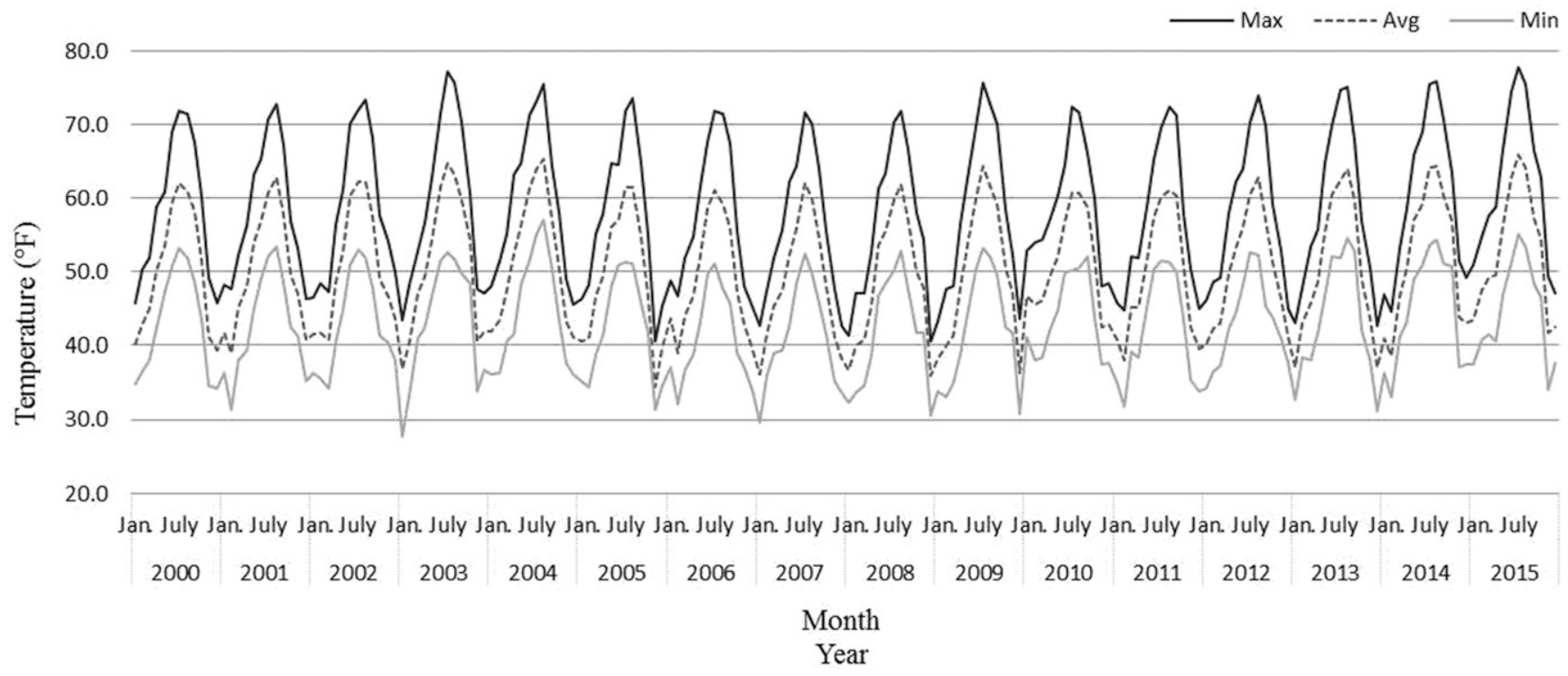

Fig. 1. Mean monthly maximum, average, and minimum air temperatures recorded from Jan. 2000 to Dec. 2015 at Washington State University Mount Vernon Northwest Washington Research and Extension Center in Mount Vernon, WA (Washington State University, 2015); $\left({ }^{\circ} \mathrm{F}-32\right) \div 1.8={ }^{\circ} \mathrm{C}$. 
Table 3. Full bloom (FB) date, categorized FB time, bloom density (BD) rating, BD index (BDI), and the categorized bloom habit of 18 apple cultivars grown and evaluated at Washington State University Mount Vernon Northwest Washington Research and Extension Center (Mount Vernon, WA), data collected a minimum of 6 years and average of 9 years.

\begin{tabular}{|c|c|c|c|c|c|}
\hline Cultivar & FB date $[ \pm$ SD $(d)]$ & FB time tim $^{\mathrm{z}}$ & $\mathrm{BD}[\text { mean } \pm \mathrm{SD}(\mathrm{d})]^{\mathrm{y}}$ & BDI $(0-1)^{x}$ & Bloom habit $^{w}$ \\
\hline Bramley's Seedling & 8 May \pm 8 & Mid & $2.8 \pm 1.3$ & 0.45 & $\mathrm{CON}$ \\
\hline Bramtot & 12 May \pm 8 & Mid & $4.1 \pm 0.8$ & 0.13 & $\mathrm{CON}$ \\
\hline Breakwell Seedling & 22 May \pm 8 & Late & $4.1 \pm 1.5$ & 0.30 & $\mathrm{CON}$ \\
\hline Bulmer's Norman & 9 May \pm 8 & Mid & $4.6 \pm 0.6$ & 0.06 & St-CON \\
\hline Campfield & 5 May \pm 10 & Early & $3.5 \pm 1.0$ & 0.19 & $\mathrm{CON}$ \\
\hline Chisel Jersey & 19 May \pm 9 & Late & $3.3 \pm 1.4$ & 0.33 & $\mathrm{CON}$ \\
\hline Grimes Golden & 2 May \pm 9 & Early & $4.6 \pm 0.4$ & 0.07 & St-CON \\
\hline Harrison & 8 May \pm 10 & Mid & $3.4 \pm 0.6$ & 0.08 & St-CON \\
\hline Kermerrien & 15 May \pm 7 & Mid & $3.1 \pm 1.7$ & 0.58 & $\mathrm{BI}$ \\
\hline Kingston Black & $14 \mathrm{May} \pm 10$ & Mid & $3.3 \pm 1.4$ & 0.40 & $\mathrm{CON}$ \\
\hline Maude & 2 May \pm 10 & Early & $4.1 \pm 1.3$ & 0.25 & $\mathrm{CON}$ \\
\hline Redstreak, Hereford & 9 May \pm 8 & Mid & $3.6 \pm 0.8$ & 0.12 & $\mathrm{CON}$ \\
\hline Yarlington Mill & 15 May \pm 9 & Mid & $3.7 \pm 1.0$ & 0.20 & $\mathrm{CON}$ \\
\hline
\end{tabular}

${ }^{\mathrm{z}}$ Based on the relative average full bloom date of the 18 cultivars, and categorized as: early, mid, or late.

${ }^{\mathrm{y}}$ Mean and SD calculated from $\mathrm{l}$ to 5 ratings where $\mathrm{l}=$ very sparse bloom, unproductive; $2=$ light bloom; $3=$ moderate bloom; $4=$ abundant bloom; and $5=$ snowball bloom, early thinning should seriously be considered to avoid biennial bearing.

${ }^{x}$ Bloom density index calculated as the absolute difference in bloom density between two consecutive years divided by their sum, index values averaged over the period of evaluation (adapted from Hoblyn et al., 1936).

${ }^{\mathrm{w}} \mathrm{St}-\mathrm{BI}=$ strongly biennial $(0.90 \leq \mathrm{BDI} \leq 1.00), \mathrm{BI}=$ biennial $(0.50 \leq \mathrm{BDI}<0.90), \mathrm{CON}=$ consistent $(0.10<\mathrm{BDI}<0.50)$, St $-\mathrm{CON}=\operatorname{strongly}$ consistent $(0.00 \leq \mathrm{BDI} \leq 0.10)$

'Geneva Tramlett's' is a tentative designation; uncertainty exists whether what was received from USDA Geneva, NY was the true 'Tramlett's Bitter'.

not vary greatly year to year during this study.

Bloom. Mean FB date for the 18 cultivars ranged from 25 Apr. to 25 May (Table 3). The earliest FB date for all cultivars occurred in 2015, which had the second highest mean spring temperature $\left(52{ }^{\circ} \mathrm{F}\right)$, and the latest FB date was in 2011 , which had the second lowest mean spring temperature $\left(47^{\circ} \mathrm{F}\right)$. Of the 18 cultivars, 6 were categorized as early-season bloomers, 9 were categorized as midseason, and 3 were categorized as late season (Table 3 ). Mean BD for the 18 cultivars was (mean \pm SD) $3.8 \pm 0.6$ with Bramley's Seedling having the lowest average BD of $2.8 \pm 1.3$ (light bloom) and Golden Russet the highest average $\mathrm{BD}$ of $4.7 \pm 0.6$ (abundant bloom) (Table 3 ). Of the 18 cultivars, I was categorized as having a biennial bloom habit, 11 were categorized as having a consistent bloom habit, and 6 were categorized as having a strongly consistent bloom habit (Table 3).

Preharvest fruit load. The mean productivity of the 18 cultivars that were rated was $2.9 \pm 0.6$, with Campfield having the lowest average productivity of $1.8 \pm 0.6$ (sparse to no fruiting), and Grimes Golden having the highest average productivity of
$4.0 \pm 0.4$ (abundant fruiting) (Table 4). Of the 18 cultivars, 4 cultivars were categorized as having biennial productivity, 10 were categorized as having consistent productivity, and 4 were categorized as having strongly consistent productivity (Table 4 ). For 15 of the 18 cultivars, blooming habit and productivity were categorized similarly. That is, these cultivars on average had either a consistent blooming habit $(\mathrm{BDI}=0.17$ ) together with consistent productivity $(\mathrm{BBI}=0.28)$, or biennial blooming habit $(\mathrm{BDI}=0.58)$ and biennial productivity $(\mathrm{BBI}=0.53)$. For three of the 18 cultivars, blooming habit was categorized as consistent (BDI = 0.34 ) and productivity was biennial $(\mathrm{BBI}=0.59)$.

Although cultivar is believed to be the main factor contributing to biennial bearing in multicultivar studies (Pellerin et al., 2011), the contrasting categorization of blooming habit and productivity for the three cultivars Bulmer's Norman, Kingston Black, and Vilberie could be a result of orchard management. Poor management (e.g., inadequate pollination or thinning) can cause inconsistent fruiting even when a cultivar consistently blooms at a high density, and proper management (e.g., targeted nutrition) can provide for consistent fruiting even when a cultivar is an unreliable bloomer (Bukovac et al., 2010). Additionally, weather factors such as late-season frost that kills blooms could also promote inconsistent fruiting (Ballard et al., 1981). In the current study, each year beehives were located immediately adjacent to the orchard and trees were fertilized consistently. However, pruning and thinning varied somewhat over the years due to fluctuation in orchard staff. As discussed by Bukovac et al. (2010), biennial fruiting is significantly influenced by environmental and biotic stresses. Growers and researchers should closely monitor fruiting and adjust management practices as needed. However, it is important to note that while biennial bearing can be managed by pruning and thinning, this involves an additional orchard management cost (Dennis, 2002; Galinato et al., 2014; Harley et al., 1942). The $\mathrm{CV}$ for the visual ratings of $\mathrm{BD}$ was $15 \%$, and the CV for productivity was $20 \%$. These moderate $\mathrm{CV}$ values were likely due to the subjectivity of the ratings, even though the same person rated $\mathrm{BD}$ and productivity every year.

Fruit sIzE. The mean fruit diameter of the 18 cultivars was $2.7 \pm$ 
Table 4. Productivity rating, biennial bearing index (BBI), and the categorized productivity of 18 apple cultivars grown and evaluated at Washington State University Mount Vernon Northwest Washington Research and Extension Center (Mount Vernon, WA) from 2011 to 2014.

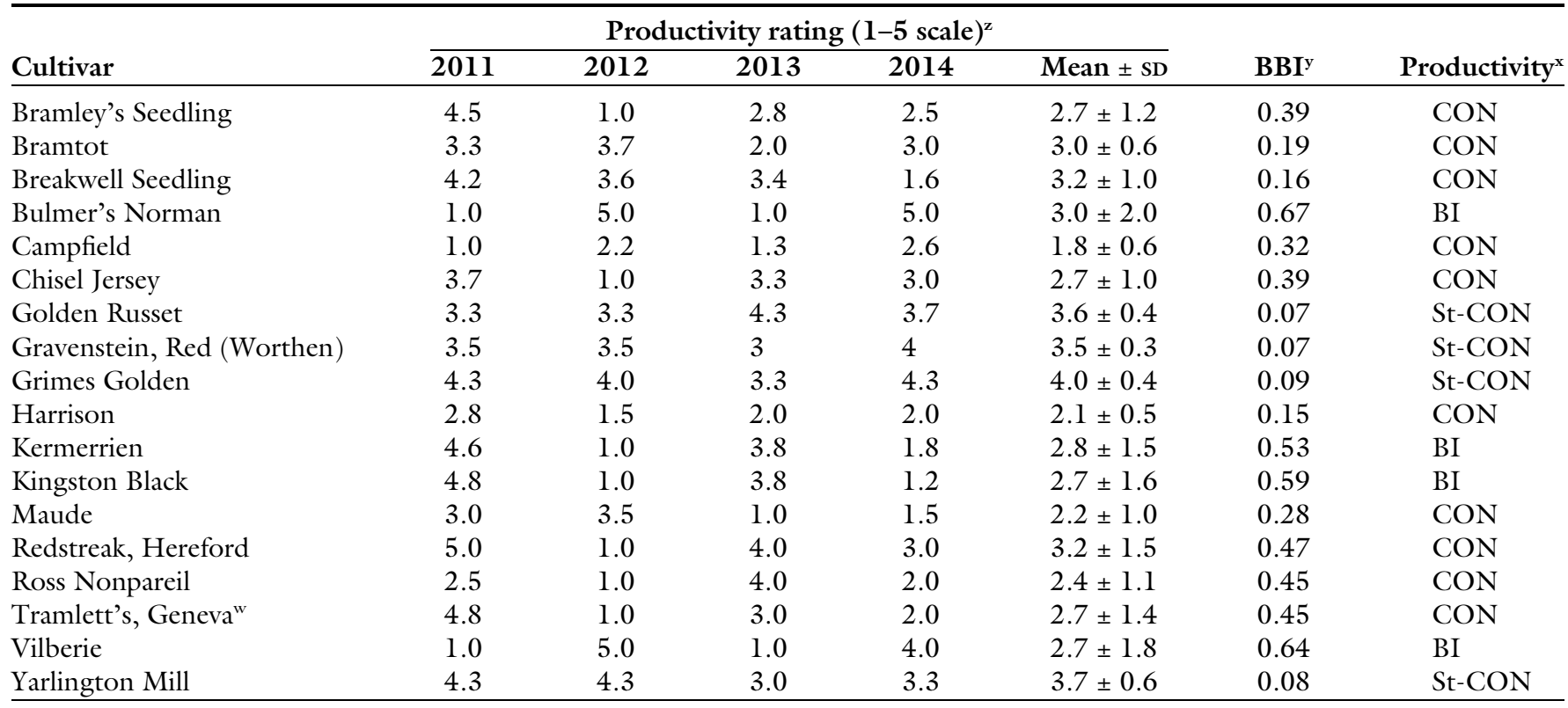

${ }^{\mathrm{z}} 1$ = sparse to no fruit, 2 = light fruiting, 3 = moderate fruiting, 4 = abundant fruiting, 5 = overloaded fruiting, multiple fruit per spur with loaded branches bending to the ground.

'Biennial bearing index calculated as the absolute difference in productivity rating between two consecutive years divided by their sum, index values averaged over the period of evaluation (adapted from Wilcox, 1944).

${ }^{\mathrm{x}} \mathrm{St}-\mathrm{BI}=$ strongly biennial $(0.90 \leq \mathrm{BBI} \leq 1.00), \mathrm{BI}=$ biennial $(0.50 \leq \mathrm{BBI}<0.90), \mathrm{CON}=$ consistent $(0.10<\mathrm{BBI}<0.50)$, St-CON $=$ strongly consistent $(0.00 \leq \mathrm{BBI} \leq 0.10)$. "'Geneva Tramlett's' is a tentative designation; uncertainty exists whether what was received from USDA Geneva, NY was the true 'Tramlett's Bitter'.

Table 5. Fruit diameter and the categorized size class of 18 apple cultivars grown at Washington State University Mount Vernon Northwest Washington Research and Extension Center (Mount Vernon, WA) from 2013 to 2015.

\begin{tabular}{lccccl}
\hline & \multicolumn{5}{c}{ Fruit diam (inches) } \\
\cline { 2 - 5 } Cultivar & $\mathbf{2 0 1 3}$ & $\mathbf{2 0 1 4}$ & $\mathbf{2 0 1 5}$ & Mean \pm SD $^{\mathrm{z}}$ & Size class $^{\mathrm{y}}$ \\
\hline Bramley's Seedling & 4.0 & 3.8 & 3.9 & $3.9 \pm 0.1$ & Large \\
Bramtot & 2.1 & 2.3 & 2.1 & $2.2 \pm 0.1$ & Small \\
Breakwell Seedling & 2.6 & 2.4 & 2.4 & $2.4 \pm 0.1$ & Medium \\
Bulmer's Norman & 3.2 & 2.8 & 3.0 & $3.0 \pm 0.1$ & Medium \\
Campfield & 2.9 & 2.9 & 2.9 & $2.9 \pm 0.0$ & Medium \\
Chisel Jersey & 2.9 & 2.7 & 2.5 & $2.7 \pm 0.2$ & Medium \\
Golden Russet & 3.0 & 2.7 & 2.8 & $2.9 \pm 0.1$ & Medium \\
Gravenstein, Red (Worthen) & 3.0 & 3.1 & 2.9 & $3.0 \pm 0.1$ & Medium \\
Grimes Golden & 3.1 & 3.2 & 3.0 & $3.1 \pm 0.1$ & Medium \\
Harrison & 2.3 & 2.4 & 2.4 & $2.3 \pm 0.1$ & Small \\
Kermerrien & 2.4 & 2.6 & 2.4 & $2.5 \pm 0.1$ & Medium \\
Kingston Black & 2.7 & 2.4 & 2.4 & $2.5 \pm 0.1$ & Medium \\
Maude & 2.4 & 3.1 & 2.8 & $2.8 \pm 0.3$ & Medium \\
Redstreak, Hereford & 2.7 & 2.9 & 2.4 & $2.6 \pm 0.2$ & Medium \\
Ross Nonpareil & 2.8 & 2.9 & 2.4 & $2.7 \pm 0.2$ & Medium \\
Tramlett's, Geneva & 2.7 & 2.4 & 2.5 & $2.6 \pm 0.1$ & Medium \\
Vilberie & 2.7 & 2.6 & 2.6 & $2.6 \pm 0.1$ & Medium \\
Yarlington Mill & 2.8 & 2.7 & 2.7 & $2.7 \pm 0.0$ & Medium \\
\hline
\end{tabular}

${ }^{\mathrm{z}}$ Average diameter of 25 fruit randomly selected at harvest each year; 1 inch $=2.54 \mathrm{~cm}$.

${ }^{\mathrm{y}}$ Small $=1.6-2.3$ inches, medium $=2.4-3.1$ inches, large $=3.2-3.9$ inches.

'Geneva Tramlett's' is a tentative designation; uncertainty exists whether what was received from USDA Geneva, NY was the true 'Tramlett's Bitter'.

0.4 inches, with Bramtot producing the smallest fruit $(2.2 \pm 0.1$ inches $)$ and Bramley's Seedling, a traditional cooking apple, producing the largest fruit ( $3.9 \pm 0.1$ inches) (Table 5$)$. Of the 18 cultivars, 2 cultivars were categorized as small-fruited $(2.3 \pm$ 0.1 inches), 15 as medium-fruited
(2.7 \pm 0.2 inches), and 1 as largefruited $(3.9 \pm 0.0$ inches) (Table 5$)$. In general, there was little variation $[\mathrm{SD}<1.00]$ in fruit size from year to year for all cultivars, indicating that fruit size was relatively consistent for the apple cultivars in this study. In comparing the fruit size data with the productivity data for all cultivars, as expected, there appeared to be an inverse correlation between productivity and fruit size, especially for the biennial bearing cultivars, as established by Monselise and Goldschmidt (1982). Fruit size is important for cider making because it affects hand harvest costs as it can take up to four times longer to pick one bin of small-sized cider fruit than large-sized fruit (A. Zimmerman, personal communication).

JUICE QUALITY CHARACTERISTICS. The mean tannin for the 18 apple cultivars was $0.20 \% \pm 0.14 \%$, and the mean TA was $0.54 \% \pm 0.28 \%$. Using the English cider classification system, 4 cultivars were classified as bittersweet (mean $0.44 \% \pm 0.09 \%$ tannin and $0.28 \% \pm 0.04 \% \mathrm{TA}), \mathrm{l}$ as bittersharp (mean $0.22 \% \pm 0.18 \%$ tannin and $0.72 \% \pm 0.27 \% \mathrm{TA}), 10$ as sharp (mean $0.11 \% \pm 0.04 \%$ tannin and $0.73 \% \pm 0.22 \% \mathrm{TA})$, and 3 as sweet 
Table 6. Tannin, titratable acidity (TA), English cider classification, specific gravity (SG), predicted alcohol by volume (ABV), and $\mathrm{pH}$ for 18 apple cultivars grown and evaluated at Washington State University Mount Vernon Northwest Washington Research and Extension Center (Mount Vernon, WA), data collected a minimum of 5 years and average of 7 years.

\begin{tabular}{|c|c|c|c|c|c|c|}
\hline Cultivar & $\begin{array}{c}\text { Tannin } \\
{[\text { mean } \pm \text { SD }(\%)]^{\mathrm{z}}}\end{array}$ & $\begin{array}{c}\text { TA } \\
{\left[\text { mean }_{ \pm} \pm \mathrm{SD}(\%)\right]^{\mathrm{y}}}\end{array}$ & $\begin{array}{c}\text { English } \\
\text { classification }^{\mathrm{x}}\end{array}$ & $\mathrm{SG}(\text { mean } \pm \mathrm{SD})^{\mathrm{w}}$ & $\operatorname{ABV}(\%)^{\mathrm{v}}$ & $\mathrm{pH}($ mean $\pm \mathrm{SD})$ \\
\hline Bramley's Seedling & $0.10 \pm 0.04$ & $1.10 \pm 0.15$ & Sharp & $1.044 \pm 0.005$ & $5.8 \pm 0.7$ & $3.15 \pm 0.31$ \\
\hline Bramtot & $0.57 \pm 0.24$ & $0.33 \pm 0.05$ & Bittersweet & $1.058 \pm 0.004$ & $7.8 \pm 0.5$ & $4.02 \pm 0.09$ \\
\hline Breakwell Seedling & $0.22 \pm 0.18$ & $0.72 \pm 0.27$ & Bittersharp & $1.042 \pm 0.005$ & $5.6 \pm 0.6$ & $3.29 \pm 0.17$ \\
\hline Bulmer's Norman & $0.20 \pm 0.05$ & $0.22 \pm 0.03$ & Sweet & $1.046 \pm 0.002$ & $6.2 \pm 0.3$ & $4.09 \pm 0.10$ \\
\hline Campfield & $0.17 \pm 0.11$ & $0.24 \pm 0.03$ & Sweet & $1.057 \pm 0.004$ & $7.6 \pm 0.6$ & $4.40 \pm 0.17$ \\
\hline Gravenstein, Red (Worthen) & $0.07 \pm 0.03$ & $0.55 \pm 0.20$ & Sharp & $1.056 \pm 0.003$ & $7.4 \pm 0.5$ & $3.55 \pm 0.41$ \\
\hline Grimes Golden & $0.07 \pm 0.03$ & $0.66 \pm 0.06$ & Sharp & $1.052 \pm 0.003$ & $7.0 \pm 0.5$ & $3.44 \pm 0.09$ \\
\hline Harrison & $0.12 \pm 0.05$ & $0.67 \pm 0.21$ & Sharp & $1.060 \pm 0.005$ & $8.0 \pm 0.7$ & $3.45 \pm 0.26$ \\
\hline Kermerrien & $0.33 \pm 0.09$ & $0.26 \pm 0.03$ & Bittersweet & $1.051 \pm 0.006$ & $6.8 \pm 0.8$ & $3.80 \pm 0.22$ \\
\hline Kingston Black & $0.16 \pm 0.09$ & $0.61 \pm 0.10$ & Sharp & $1.057 \pm 0.007$ & $7.5 \pm 0.9$ & $3.50 \pm 0.19$ \\
\hline Maude & $0.08 \pm 0.03$ & $0.37 \pm 0.14$ & Sharp & $1.050 \pm 0.002$ & $6.7 \pm 0.2$ & $3.68 \pm 0.51$ \\
\hline Vilberie & $0.44 \pm 0.20$ & $0.28 \pm 0.07$ & Bittersweet & $1.043 \pm 0.004$ & $5.5 \pm 0.6$ & $3.91 \pm 0.14$ \\
\hline Yarlington Mill & $0.19 \pm 0.09$ & $0.23 \pm 0.10$ & Sweet & $1.047 \pm 0.009$ & $6.3 \pm 1.2$ & $4.14 \pm 0.34$ \\
\hline
\end{tabular}

"The term "tannin" is used in adaptation of cider literature; expressed as tannic acid equivalents, in percent.

${ }^{\mathrm{y}}$ Expressed as malic acid equivalents, in percent.

${ }^{\mathrm{x}}$ English cider classification system: bittersweet $(>0.20$ tannin, $<0.45$ acid $)$, bittersharp $(>0.20$ tannin, $>0.45$ acid $)$, sharp $(<0.20$ tannin, $>0.45$ acid $)$, sweet $(<0.20$ tannin, $<0.45$ acid).

wThe ratio of the density of the juice to the density of pure water, unitless.

'Prediction based on specific gravity of juice, using the equation: $\mathrm{ABV}$ (percent) $=[(\mathrm{SG}-1.0) \times 1000] / 7.5$.

"Geneva Tramlett's' is a tentative designation; uncertainty exists whether what was received from USDA Geneva, NY was the true 'Tramlett's Bitter'.

(mean $0.19 \% \pm 0.01 \%$ tannin and $0.23 \% \pm 0.01 \%$ TA) (Table 6). In comparison with historical juice quality [recorded 1905-75, data not shown (Beech and Carr, 1977)], three of the cultivars, Bulmer's Norman, Kingston Black, and Yarlington Mill, performed differently at WSU Mount Vernon NWREC than at LARS. More specifically, these three cultivars on average achieved a tannin content less than or equal to $0.20 \%$ at WSU Mount Vernon NWREC and greater than $0.20 \%$ at LARS (where they were classified as bitter). This difference in classification was also found by Alexander et al. (2016), which attributed the differences in cultivar tannin at WSU Mount Vernon NWREC and LARS to differential cultural practices. At WSU Mount Vernon NWREC, apple trees were grown with more intense water and nutrient management than at LARS, and Lea and Beech (1978) established a positive correlation between tree stress and fruit tannin content. The CV for tannin was $68 \%$, and was $52 \%$ for TA. The large cV for tannin from year to year was not surprising given similar findings by Alexander et al.
(2016) and Valois et al. (2006) in which multiple cider cultivars were evaluated over multiple years in Washington and New York, respectively. The large cv for TA indicates this characteristic is also variable from year to year.

The mean SG of the 18 cultivars was $1.052 \pm 0.007$ and the average predicted ABV was calculated to be $6.9 \% \pm 0.9 \%$, with Vilberie providing the lowest predicted ABV $(5.5 \% \pm$ $0.6 \%$ ) and Golden Russet the highest predicted ABV $(8.7 \% \pm 0.9 \%)$ (Table $6)$. Predicting ABV is important as each cider maker will likely have a targeted final $\mathrm{ABV}$, and the alcohol content influences the cider-making process from the selection of a yeast strain to timing of bottling the finished product. The average $\mathrm{pH}$ of the 18 cultivars was $3.68 \pm 0.39$ with Bramley's Seedling having the lowest $\mathrm{pH}(3.15 \pm 0.31)$ and Campfield having the highest $\mathrm{pH}(4.40 \pm 0.17)$ (Table 6). Cider makers generally target a $\mathrm{pH}$ range of $3.3-3.7$ as this is optimal for fermentation (Mitchell, 2009). Juice quality characteristics measured in the current study differed somewhat from measurements in other studies, potentially due to differences in fruit maturity at time of harvest. The Swedish researchers in Heikefelt (2011) harvested and pressed all cultivars at the same time regardless of level of maturity. The American researchers in Ewing (2016) harvested each cultivar based on typical fruit maturity for commercial dessert fruit. At LARS, much of the research of fruit quality was conducted with fruit that had fallen to the ground and so could be considered fully mature at time of harvest (Lea, 2014). In the current study, each cultivar was harvested when fruit were fully ripe according to the starch index test $(8.5$ on a scale of $1-9)$.

\section{Conclusions}

Evaluation results of 17 cider apple cultivars plus one standard dessert apple cultivar for bloom time, $\mathrm{BD}$, bloom habit, productivity, fruit size, and juice quality characteristics indicate that U.S. cider apple growers and cider makers have a wide range of choices, as expected. Cultivars Golden Russet (sharp), Grimes Golden (sharp), and Yarlington Mill (sweet, but borderline bittersweet) were 
strongly consistent in productivity in the current study, and all produced medium-sized fruit (easier for hand harvest); however, none of these cultivars produced high levels of tannin. Cultivars Bramtot (bittersweet, small fruit), Chisel Jersey (bittersweet, medium fruit), and Breakwell Seedling (bittersharp, medium fruit) were consistent in productivity and produced high levels of tannin. However, cultivar selection is often based on factors additional to yield. For example, bloom time is of high importance to growers in regions where fire blight (caused by the bacterium Erwina amylovora) occurs as disease incidence is strongly correlated with later flowering (Smith, 2012). The early blooming cultivars Campfield and Golden Russet may be well suited for regions in which fire blight is prevalent as they bloom early and have consistent bloom and fruit habit. However, cider makers may not prefer these fruit as they were classified as sweet in the current study and thus would not alone provide the sharp, bitter, or astringent characteristics that are currently sought after in the industry. Cider makers could compensate by blending with other juice or adding exogenous malic acid and tannin to the juice (Gerling et al., 2015). Growers are advised to compare the mean bloom date of 'Red Gravenstein' in their area to the bloom date in this study to determine the relative expected bloom date for each cider cultivar in this study for their area. For growers that do not have access to 'Red Gravenstein', WSU Extension Bulletin EB 1436 provides a number of alternate standard dessert apple cultivars that were grown at the same site of this study for comparison (e.g., Jonagold is a midseason bloomer and Red Delicious is a late season bloomer; Norton and King, 1987).

Tannin is of special interest to cider makers, and while growers may select cultivars that tend to have relatively high tannin, the relatively high variation in tannin from year to year in the current study indicates this juice characteristic must be measured each year. If tannin is lower than anticipated any given year, cider makers could blend with other juice or add exogenous tannin to the juice as mentioned above. However, it is important to note that the term "tannin" is used loosely in this study, serving as a general indicator of bitterness and astringency as adapted from classic cider literature. Research is underway here and in other regions to provide for an analytical method that best quantifies the polyphenol classes underlying the characteristics of bitterness and astringency, both which provide a more in-depth measure of tannin (Ewing, 2016). The high variation in TA also indicates this characteristic is variable from year to year, and thus needs to be measured each year. Since TA is a linear scale, some experienced cider makers adjust TA levels to reach the optimal $\mathrm{pH}$ range (generally, 3.3-3.8); in contrast, $\mathrm{pH}$ is a logarithmic scale and buffering can further complicate $\mathrm{pH}$ adjustments (Mitchell, 2009).

This study provides a baseline for characterizing numerous cider apple cultivars grown in the United States, and data collection is ongoing with annual results posted on our website (Miles, 2017). Additional years of performance data will further elucidate the characteristics of each cultivar, and additional cultivars have been planted but are yet to be evaluated (e.g., Bedan de Parts, Fillbarrel, and Hewes' Virginia Crab, planted in 2014). Given that environmental and management conditions can influence bloom habit and fruit characteristics, and that the current study was conducted at just one location, although across 16 years, other conditions (e.g., climate, fertilizer, pruning, irrigation) might lead to different outcomes. Thus, more long-term studies with multiple sites and greater replication are needed to establish a better understanding of how each cultivar responds in various locations. The effects of rootstocks, $\mathrm{BD}$, and irrigation and fertilizer regimes on juice quality also need further investigation. Additionally, the cider characteristics of each cultivar need to be evaluated as juice quality measurements may be insufficient to ascertain the qualities that each cultivar will bring to a finished cider product. Evaluation of single cultivar ciders is currently being carried out at WSU and results will be forthcoming. The resources for cider experimentation have been relatively limited to date (limited number of bearing acres, and few research orchards with replication), but growers need information such as provided in the current study and upcoming studies to determine which cultivars to plant to meet the increasing demand for specialty cider apples in the United States.

\section{Literature cited}

Alexander, T., J. King, A. Zimmerman, and C.A. Miles. 2016. Regional variation in juice characteristics of four cider apple (Malus domestica $\times$ Borkh.) cultivars in central and northwest Washington. HortScience 51:1-5.

Alcohol and Tobacco Tax and Trade Bureau (TTB). 2015. Code of federal regulations, 27 CFR Part 24. U.S. Dept. Treasury, Washington DC.

Alcohol and Tobacco Tax and Trade Bureau (TTB). 2016. Cider statistics CY 2007-2015. TTB, Washington, DC.

Alwood, W.B. 1903. A study of cider making. U.S. Dept. Agr., Bur. Chem. Bul. No.71.

Ballard, J.K., E.L. Proebsting, R.B. Tukey, P.J. Chapman, C. Strausz, and H. Mills. 1981. Critical temperatures for blossom buds. Washington State Univ. Ext. Publ. EB091.

Barker, B.T.P. 1903. Classification of cider apples. Natl. Fruit Cider Inst., Long Ashton Res. Sta., Bristol, England.

Barker, B.T.P. 1911. Cider-making. J. Royal Hort. Soc. 36:570-573.

Barker, B.T.P. and L.F. Burroughs. 1953. Cider apple varieties then and now: A survey of vintage-quality trials, p. 45-55. In: T. Wallace and R.W. Marsh (eds.). Science and fruit. Univ. Bristol, Bristol, England.

Beech, F.W. and J.G. Carr. 1977. Cider and perry, p. 139-313. In: A.H. Rose (ed.). Economic microbiology. Vol. 1. Alcoholic beverages. Academic Press, London, UK.

Bender, D.A. 2009. A dictionary of food and nutrition. 3 ed. Oxford Univ. Press, Oxford, England.

Blanpied, G.D. and K.J. Silsby. 1992. Predicting harvest date windows for apples. Cornell Info. Bul. No. 221.

Bore, J.M. and J. Fleckinger. 1997. Pommieres a cidre: Varieties de France. 22 Feb. 2017. <http://www.ifpc.eu/ fileadmin/users/ifpc/infos_techniques/ Varietes_cidricoles.pdf $>$.

Buell, J.S. 1869. Cider makers' manual. Haas and Kelley, Buffalo, NY.

Bukovac, M.J., P. Sabbatini, F. Zucconi, and P.G. Schwallier. 2010. A long-term study on native variation of flowering and 
fruiting in spur-type 'Delicious' apple. HortScience 45:22-29.

Burroughs, L.F. and G.C. Whiting. 1960. Annual report Long Ashton Research Station. Long Ashton Res. Sta., Bristol, England.

Chu, C.I.G. and K.R. Wilson. 2000. Evaluating maturity of 'McIntosh' and 'Red Delicious' apples. Ontario Ministry Agr. Food Rural Affairs Publ. Order No. 00-025. 22 Mar. 2016. <http://www. omafra.gov.on.ca/english/crops/facts/ 00-025.htm>.

Dennis, F.D., Jr. 2002. Mechanisms of action of apple thinning chemicals. HortScience 37:471-474.

Ewing, B. 2016. Managing apple maturity and storage to improve the quality of Virginia hard ciders. MS Thesis, Virginia Polytechnic Inst. State Univ., Blacksburg, VA.

Galinato, S.P., R.K. Gallardo, and C.A. Miles. 2014. Cost estimation of establishing a cider apple orchard in western Washington. Washington State Univ. Ext. Publ. FS141E.

Gallander, J., L. Briner, J. Stetson, J.-W. Liu, L. Kreilow, K. Walker, R. Romberger, C. Stamp, and R. Reisen. 1991. Manual for wine analysis and laboratory techniques. Ohio State Univ., Ohio Agr. Res. Dev. Ctr., Wooster, $\mathrm{OH}$.

Gerling, C.J., C.K. McGregor, A.K. Mansfield, M.E. Sugrue, and O.L. Padilla-Zakour. 2015. Commercial tannin addition to increase polyphenolic content of ciders made from popular NY apples. 22 Feb. 2017. <http://www. ciderassociation.org/resources/Documents/ Tannin\%20additions.pdf>

Harley, C.P., J.R. Magness, M.P. Masure, L.A. Fletcher, and E.S. Degman. 1942. Investigations on the cause and control of biennial bearing of apple trees. USDA Tech. Bul. No. 792.

Heikefelt, C. 2011. Chemical and sensory analyses of juice, cider and vinegar produced from different apple cultivars. MS Thesis, Swedish Univ. Agr. Sci., Alnarp, Sweden.

Hoblyn, T.N., N.H. Grubb, and A.C. Painter. 1936. Studies in biennial bearing. Intl. J. Pomol. 14:39-76.

Jolicoeur, C. 2013. The new cider maker's handbook: A comprehensive guide for craft producers. Chelsea Green Publ., White River Junction, VT.

Lau, O.L. 1988. Harvest indices, dessert quality, and storability of 'Jonagold' apples in air and controlled atmosphere storage. J. Amer. Soc. Hort. Sci. 113:564-569.
Lea, A. 2008. Craft cider making. 3rd ed. Good Life Press, Preston, UK.

Lea, A. 2014. Cidermaking, p. 148-195. In: C.W. Bamforth and R.E. Ward (eds.). The Oxford handbook of food fermentations. Oxford Univ. Press, New York, NY.

Lea, A.G.H. and F.W. Beech. 1978. The phenolics of ciders: Effects of cultural conditions. J. Sci. Food Agr. 29:493-496.

Lowenthal, J. 1877. Uber die Bestimmung des Gerbstoffs. Fresenius Z Anal. Chem. 6:33-48.

Merwin, I.A., S. Valois, and O. PadillaZakour. 2008. Cider apples and cidermaking techniques in Europe and North America. Hort. Rev. 34:365-414.

Micke, W.C., J.A. Grant, M.V. Norton, and J.T. Yeager. 1991. Thinning Granny Smith apples chemically. Calif. Agr. 45(1): 30-32.

Miles, C.A. 2017. Cider research at WSU NWREC. 22 Feb. 2017. <http://www. cider.wsu.edu/>

Mitchell, P. 2009. Cider \& perry production: Principles \& practice course notes. Mitchell F\&D, Newent, UK.

Monselise, S.P. and E.E. Goldschmidt. 1982. Alternate bearing in fruit trees. Hort. Rev. 4:128-173.

Morgan, J. and A. Richards. 1993. The book of apples. Ebury Press, London, UK.

Morton, A. 2013. U.S. cider still taking bite out of beer: C\&C Group. Just-drinks website. 30 Oct. 2013. <http://www. just-drinks.com/analysis/just-on-call-uscider-still-taking-bite-out-of-beer-ccgroup_idl11932.aspx>.

Moulton, G.A. and J. King. 2003. Fruit thinning for high quality. 16 Dec. 2016. $<$ http://ext100.wsu.edu/maritimefruit/ fruit-thinning-for-high-quality $/>$.

Moulton, G.A., C.A. Miles, J. King, and A. Zimmerman. 2010. Hard cider production \& orchard management in the Pacific Northwest. Washington State Univ. Ext. Publ. PNW621.

Northwest Cider Association. 2016. Northwest cider association members. 10 Apr. 2016. <http://www.nwcider.com/ washington-cidermakers $/>$.

Norton, R.A. and J. King. 1987. Apple cultivars for Puget Sound. Washington State Univ. Ext. Pub EB1436.

Orton, V. 1995. The American cider book: The story of America's national beverage. North Point Press, New York, NY.

Pellerin, B.P., D. Buszard, D. Iron, C.G. Embree, R.P. Marini, D.S. Nichols, G.H.
Neilsen, and D. Neilsen. 2011. A theory of blossom thinning to consider maximum annual flower bud numbers on biennial apple trees. HortScience 46:40-42.

Power, G. n.d. Best cider fruits, p. 30-34. In: W.B. Alwood. A study of cider making. U.S. Dept. Agr., Bur. Chem. Bul. No. 71.

Proulx, A. and L. Nichols. 1997. Cider: Making, using, and enjoying sweet and hard cider. 3rd ed. Storey Publ., North Adams, MA.

Smith, T. 2012. Fire blight management in the Pacific Northwest. 20 Dec. 2016. <http://extension.wsu.edu/chelan-douglas/ agriculture/treefruit/pestmanagement/ fireblight $/>$.

Stebbins, R. 1992. Training apple trees in commercial orchards. Oregon State Univ. Ext. Pub. PNW0402.

The Cyder Market. 2015. Domestic cider: Washington cidermakers. 9 Mar. 2016. <https://www.cydermarket.com/washington. html .

Trowbridge, J.M. 1917. The cider makers' hand book: A complete guide for making and keeping pure cider. Orange Judd, New York, NY.

U.S. Department of Agriculture (USDA). 2013. Web soil survey. 17 Sept. 2013. <http://websoilsurvey.nrcs.usda.gov>.

Valois, S., I.A. Merwin, and O.I. PadillaZakour. 2006. Characterization of fermented cider apple cultivars grown in upstate New York. J. Amer. Pomol. Soc. 60:113-128.

Washington State University. 2015. AgWeatherNet weather data: Climate summary. 21 Mar. 2016. <http://weather.wsu. edu/awn.php?page=stationdetails\&UNIT_ ID $=330101>$.

Watson, B. 1999. Cider hard and sweet: History, traditions, and making your own. Countryman Press, Woodstock, VT.

Webster, A.D. 1995. Rootstock and interstock effects on deciduous fruit tree vigour, precocity, and yield productivity. N. Z. J. Crop Hort. Sci. 23:373-382.

Wilcox, J. 1944. Some factors affecting apple yields in the Okanagan Valley: Tree size, tree vigor, biennial bearing, and distance of planting. Sci. Agr. 25:189.

Williams, R.R. 1975. An introduction to modern cider apple production. Long Ashton Res. Sta., Bristol, England.

Williams, R.R. 1987. Bulmer's Pomona. Fourth Estate, London, UK.

Williams, D.R. 1990. Hard cider's mysterious demise. 22 Feb. 2017. <http:// mason.gmu.edu/ drwillia/cider.html>. 